\title{
Control design of damper mass spring system based on backstepping controller scheme
}

\section{International Review of Applied Sciences and Engineering}

11 (2020) 2, 181-187

DOI:

$10.1556 / 1848.2020 .20049$

(c) 2020 The Authors

\section{ORIGINAL RESEARCH} PAPER

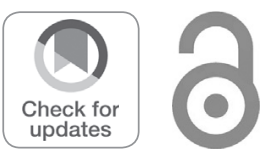

*Corresponding author.

E-mail: noormjeed@yahoo.com

\author{
MUNAF FATHI BADR ${ }^{1}$ (D), EKHLAS HAMEED KARAM ${ }^{2}$ (D) and \\ NOOR MOHAMMAED MJEED ${ }^{2 *} \odot$ \\ ${ }^{1}$ Mechanical Engineering Department, College of Engineering, Mustansiriyah University, Baghdad, \\ Iraq \\ ${ }^{2}$ Computer Engineering Department, College of Engineering, Mustansiriyah University, Baghdad, \\ Iraq
}

Received: September 15, 2019 • Accepted: November 10, 2019

Published online: July 17, 2020

\section{ABSTRACT}

The objective of this paper is to present a proposed control model for the electromechanical damper mass spring system including the backstepping technique in comparison with the conventional proportional-derivative-integral (PID) controller unit to realize the best performance of the control systems. The suggested approach demanded the construction in laboratory arrangement of damper mass spring system which linked with electrical position sensor, and the theoretical work involved the derivation of the required mathematical equations in order to formulate the simulation models in Matlab software package. The obtained results show that the backstepping control technique provides the better performance associated with stable control system especially with increasing the value of selected mechanical load.

\section{KEYWORDS}

electromechanical system, backstepping technique, PID controller, simulation

\section{INTRODUCTION}

In the recent decades, damper mass spring systems are widely used in different areas of engineering field applications. They have been applied in most dynamics suspension systems to provide more reliability of the design requirements such as increasing the factors of safety or absorbing the impact forces [1-2]. They can be categorized into passive and active mechanical elements, the passive control mechanical elements are represented by springs and dampers parts while active elements can be subdivided into various kinds of sensors and actuators equipment [3-4]. Actually many forms of electronic control devices have been inserted in some application of mechanical vibration control system in order to gain more sensible reduction in the measurement of vibration level. For that, the damper mass spring systems can be arranged in various control configurations to improve the behaviour of the employed control systems and to meet the required demands of the control application [5-8].

Besides, many researchers in a lot of literatures have been concerned with damper mass spring systems applications and carried out multiple theoretical and experimental studies. Some of these literatures focused on the study of the dynamic response characteristics of the mechanical elements in the applied system, while the others dealing with the analysis of control system depended on the related mathematical models in order to carry out the computer simulation process of the specified damper mass spring system [1-13]. The main purpose of this work is to attempt to use different controller models for selective electromechnical systems consisting of series combination of damper mass spring elements connected with position sensor. To realize this goal, two forms of controller units have been used; the first one is the classical proportional-derivative-integral controller (PID), while the other is the backstepping controller technique. 
Backstepping represents as controller technique which can be applied for various dynamical systems to obtain a stable control model especially for nonlinear dynamical systems. In brief, the backstepping method refers to the control process that is based on the systematic and recursive design in application of feedback control model for various systems [13-16]. One of the merits of this technique is the ability to employ a new control Lyapunov function (CLF) for the selected control system that permits an analysis approach for the characteristics parameters of the closed loop system. Contrary to a lot of feedback linearization methods in which the problems of the precise model or cancellation of the useful nonlinear terms may occurr, the backstepping technique can permit a proper choice of designing tools for the purpose of accommodating of nonlinearities and it can be used to prevent the unwanted cancellation. The biggest advantage of the backstepping approach as compared with other control methods lies in its design flexibility merit according to its recursive use of Lyapunov functions [12-20]. The simulation process of the employed electromechanical control system will be run via Matlab software package based on the obtained physical parameters of the mechanical elements and the corresponding mathematical models. The step input response for each control model will be applied in simulation process and according to the outcoming simulation results; the comparisons will be done between the employed controller units by using different values of mechanical loads to observe the best response of each control model.

This paper has been organized as in the following. The construction and the mathematical models of the employed damper mass spring systems are introduced in Section 2. The controlled models of the suggested electromechanical system will be described in Section 3. The Matlab simulation process involving the displayed results are presented in Section 4 while Section 5 contained the conclusions.

\section{THE CONSTRUCTION AND MATHEMATICAL MODELS OF THE ELECTROMECHANICAL SYSTEM}

The electromechanical system under consideration consists of damper, mass and spring elements beside electrical position sensor as shown in Fig. 1. In laboratory, the mechanical parts have been mounted vertically in series combination and connected in parallel configuration with electrical position which has been mechanically linked with the platform that carries the mechanical load. The electrical position sensor will be responsible to detect the mass displacement that occurs due to applying different values of mechanical load at the platform. The tolerance in the position of the platform will be measured with respect to the reference point that has previously been determined. Practically, the position sensor acts as a variable electrical resistance element which consists of movable iron core that provides a linear sliding motion and smooth contact with

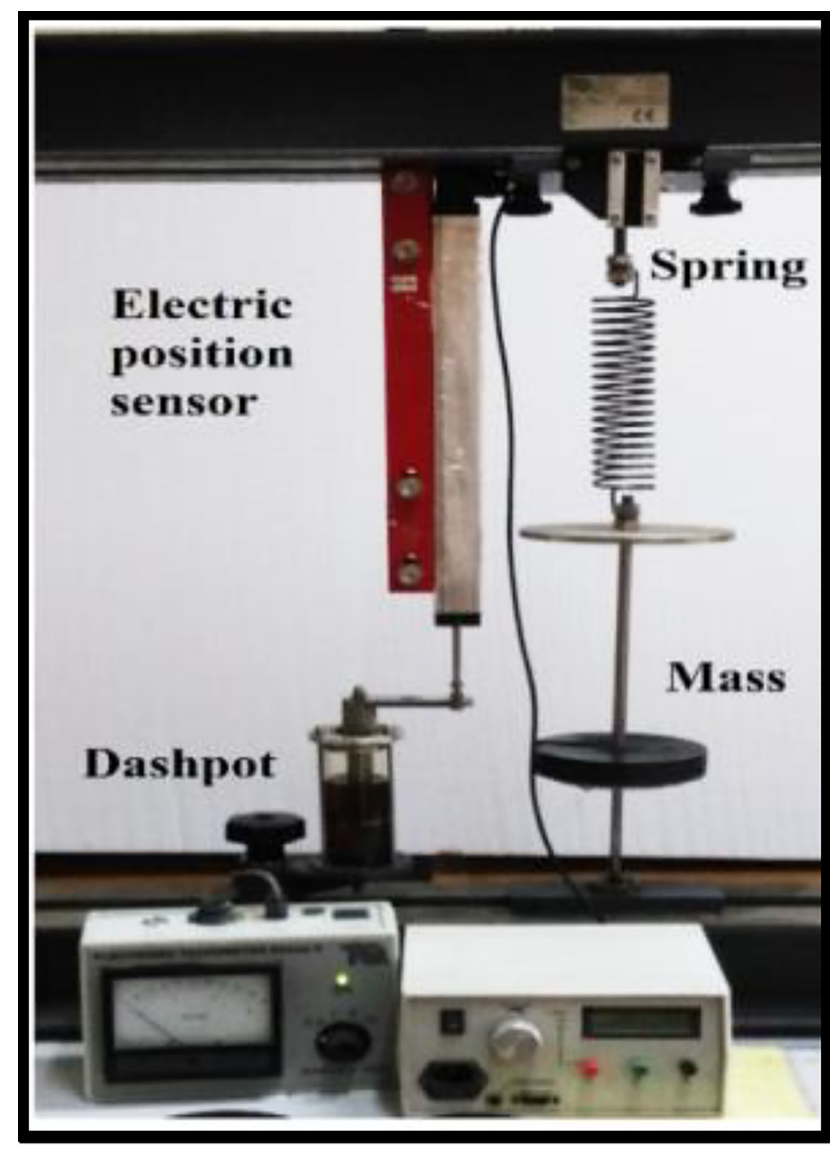

Fig. 1. The apparatus of the employed electromechanical system

fixed resistance. It has a maximum value of electrical resistance equal to $(530 \Omega)$, while the stroke length of the iron core is equal to $(250 \mathrm{~mm})$ [9]. The sensor has been connected to electrical unit which has been designed to convert the different values of the tolerance in the position distance to the corresponding electrical voltage signals.

To obtain the corresponding mathematical models of the suggested electromechanical system, it will be required to obtain the required mathematical equations for the mechanical and electrical subsystems. For the mechanical subsystem, the Newton's law will be applied to obtain the net force as in the following [20-22]:

$$
\sum_{i=1}^{3} f_{i}=f_{1}+f_{2}+f_{3},
$$

where

$$
\begin{gathered}
f_{1}=m \frac{d^{2} x}{d t^{2}}, \\
f_{2}=b \frac{d x}{d t}, \\
f_{3}=k x,
\end{gathered}
$$

The mechanical subsystem consists of three kinds of elements, the first item is a mass $(m)$, and the second one is a damped coefficient $(b)$ and finally the spring constant $(k) . f_{1}$, 
$f_{2}$ and $f_{3}$ represents inertial, viscous and spring restoring forces and measured in $(N)$. Therefore, the sum of the mechanical forces of the damper mass spring system can be calculated as in the following:

$$
f_{t}=m \frac{d^{2} x}{d t^{2}}+b \frac{d x}{d t}+k x
$$

Equation (5) represents the mathematical model of the damper mass spring system under consideration in which the parameter $(x)$ represents the displacement of mass that is measured from equilibrium position. Taking the Laplace transform for Eq. (5) under zero initial conditions, the transfer function of the applied mechanical system will be represented as shown in Eq. (6).

$$
\frac{X(s)}{F_{t}(s)}=\frac{1}{\left(m s^{2}+b s+k\right)},
$$

For the electrical subsystem and according to the characteristics of the employed position sensor as variable resistance, the output voltage signal from the sensor unit can be determined as in the following $[8,9]$ :

$$
V_{\text {sensor }}=I_{\text {sensor }} \times R_{\text {sensor }},
$$

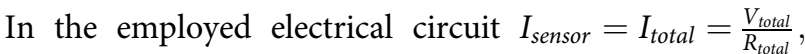
where

$V_{\text {sensor }}, V_{T}$ represent the output voltage from the sensor and the total applied voltage $(\mathrm{V})$.

$R_{\text {sensor }}$ represents the electrical resistance of the position sensor $(\Omega)$.

$$
V_{\text {sensor }}=V_{T} \times \frac{R_{\text {sensor }}}{R_{\text {total }}}
$$

Hence, to calculate the change of the movement $\mathrm{x}(\mathrm{t})$ with respect to time due to applied various values of mechanical load, the position sensor will send an electrical voltage signal proportional to the net of displacement in the system position.

\section{THE CONTROLLED MODELS OF THE ELECTROMECHANICAL SYSTEM}

The block diagram of the proposed controlled damper mass spring system is shown in Fig. 2.

The suggested approach of the electromechanical damper mass spring control system will be subdivided into the following control models:

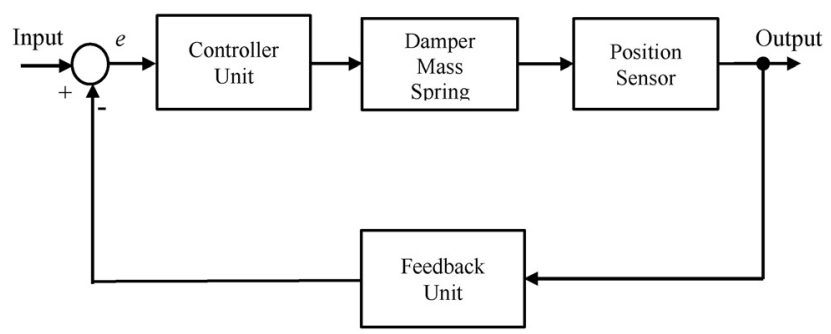

Fig. 2. The proposed control model of the electromechanical system i) Control model with using PID controller unit

To maintain the required structure of the closed loop control system with using PID controller and unity feedback element, it is required to employ and calculate the following transfer functions [20-22]:

$G_{1}=$ the transfer function of the damper mass spring system.

$G_{2}=$ the transfer function of the position sensor.

$G_{C}=$ the transfer function of the PID controller unit.

And $\left(G_{1}, G_{2}\right.$ and $\left.G_{C}\right)$ can be expressed as follows:

$$
\begin{gathered}
G_{1}=\frac{1}{\left(m s^{2}+b s+k\right)}, \\
G_{2}=\frac{V}{x}, \\
G_{C}=\left(K p+\frac{K i}{s}+K d s\right),
\end{gathered}
$$

where

$m=$ the mass of mechanical load $(\mathrm{g})$.

$c=$ damping coefficient of the dashpot $(\mathrm{Ns} / \mathrm{m})$.

$k=$ stiffness coefficient of the spring $(\mathrm{N} / \mathrm{m})$.

$V=$ the electrical voltage signal of the position sensor $(\mathrm{V})$.

$x=$ the tolerance in the distance $(\mathrm{m})$.

$K_{\mathrm{P}}=$ the proportional gain parameter of the PID.

$K_{\mathrm{i}}=$ the integral gain parameter of the PID.

$K_{\mathrm{d}}=$ the derivative gain parameter of the PID.

Taking $G_{T}=\left(G_{C}\right) *\left(G_{1}\right) *\left(G_{2}\right)$

Hence, the overall transfer function of the entire control system $\left(G_{s y s}\right)$ will be formed as follows [18]:

$$
G_{s y s}=\frac{G_{T}(s) H(s)}{1+G_{T}(s) H(s)},
$$

With taking unity feedback $H(s)=1$, then

$G_{s y s}=\frac{V\left(K d s^{2}+K p s+K i\right)}{x^{*} m s^{3}+\left(x^{*} c+V^{*} K d\right) s^{2}+\left(V^{*} K p+x^{*} k\right) s+V^{*} K i}$,

ii) Electromechanical Control system based on Backstepping Technique

The backstepping control design can be illustrated for the damper mass spring control system with applying the following steps [10-14]:

Step 1 The mathematical differential equation of the suggested damping system is given by:

$$
\frac{d^{2} x}{d t^{2}}+\left(\frac{b}{m}\right) \frac{d x}{d t}+\left(\frac{k}{m}\right) x=\left(\frac{1}{m}\right) u,
$$

where $(u)$ represents the external force.

The Eq. (14) can be rewritten as

$$
m \ddot{x}=-k x-b \dot{x}+u,
$$

Rearranging Eq. (15) as follows 


$$
\ddot{x}=-\frac{k}{m} x-\frac{b}{m} \dot{x}+\frac{1}{m} u,
$$

Hence

$$
\ddot{x}=F(x)+g(t) u(t)+d(t),
$$

where:

$F(x)=-\frac{k}{m} x-\frac{b}{m} \dot{x}$, and $g(t)=\left(\frac{1}{m}\right) u$,

$d(t)$; represents the external disturbance.

$x, u(t)$; represent the inputs for the control unit.

The tracking error can be defined as follows:

$$
e_{1}=\left(x_{d}-x\right),
$$

Then, the tracing error derivative can be represented as follows:

$$
\dot{e}_{1}=\left(\dot{x}_{d}-\dot{x}\right),
$$

The first Lyapunov function will be taken as follows:

$$
V_{1}=\frac{1}{2} e_{1}^{T} e_{1},
$$

And the derivative of the first Lyapunov function will become as

$$
\begin{gathered}
\dot{V}_{1}=e_{1}^{T} \dot{e}_{1}=e_{1}^{T}\left(\dot{x}_{d}-\dot{x}\right), \\
\beta=\dot{x}_{d}+k_{1} e_{1},
\end{gathered}
$$

Where $k_{1}$ represents the positive constant.

If the virtual control is replaced with the desired value, then Eq. (21) becomes:

$$
\dot{V}_{1}=-k_{1} e_{1}^{T} e_{1} \leq 0,
$$

And $e_{2}=(\dot{x}-\beta)$.

Then $e_{2}=\left(\dot{x}-\dot{x}_{d}-k_{1} e_{1}\right)$.

The sliding surface will be defined in terms of the error as:

$$
s=e_{2}=(\dot{x}-\beta)=\left(\dot{x}-\dot{x}_{d}-k_{1} e_{1}\right),
$$

Step 2 In this step of the backstepping control technique, the second Lyapunov function will be selected as follows [14-19]:

$$
V_{2}=V_{1}+\frac{1}{2} s^{T} s
$$

And

$$
\dot{V}_{2}=V_{1}+\frac{1}{2} s^{T} \dot{s},
$$

$\dot{V}_{2}=e_{1}^{T}\left(-e_{2}-\lambda_{1} e_{1}\right)+s^{T}\left(F(x, t)+g(t) u(t)+d(t)-\ddot{x}_{d}-k_{1} \dot{e}_{1}\right.$, $\dot{V}_{2}=e_{1}^{T}\left(-e_{2}-\lambda_{1} e_{1}\right)+s^{T}\left(F(x, t)+g(t) u(t)+d(t)-\ddot{x}_{d}-k_{1} \dot{e}_{1}\right.$, $\dot{V}_{2}=-\lambda_{1} e_{1}^{T} e_{1}+s^{T}\left(-e_{1}+F(x, t)+g(t) u(t)+d(t)-\ddot{x}_{d}-k_{1} \dot{e}_{1}\right)$,
Step 3 The external disturbance will be assumed as unknown, then the backstepping control scheme in final control signal can be obtained as follows:

$$
u=\frac{1}{g(t)}\left(-F(x, t)-k_{2} s+e_{1}+k_{1} \dot{e}_{1}-\ddot{x}_{d}\right)
$$

\section{SIMULATION PROCESS AND RESULTS}

The simulation process of the proposed controlled models for the damper mass spring has been carried out using Matlab software. It has been runt based on the practical measuring values of the stiffness coefficient for the employing spring as well as the damping factor of the dah pot. These parameters values are equal to $408.2 \mathrm{~N} / \mathrm{m}$ for the spring coefficient and nearly a $17.889 \mathrm{Ns} / \mathrm{m}$ for the damping coefficient of the dash pot has [8].

In the practical work with using the laboratory test bench of damper mass spring system, it was found when applying mechanical load equal to $400 \mathrm{~g}$ the tolerance in the displacement will be equal to $5.5 \mathrm{~mm}$ with respect to equilibrium position and the corresponding measuring value of the electrical voltage signal sending from the position sensor will be equal to $470 \mathrm{mV}$.

This practical test procedure has been repeated with applying different values of mechanical load such as 800 , 1,200 and $1,600 \mathrm{~g}$ and the obtained results for the net displacement of the damper mass spring system will be equal to $6.3,7.2$ and $8.1 \mathrm{~mm}$, respectively. The related corresponding values of the voltage signals sending from the position sensor have been equal to 600,730 and 870 $\mathrm{mV}$ [8].

Starting with running the simulation control model with conventional PID controller unit and taking arbitrary values of the gain factors such as $K_{p}=1, K_{d}=1$ and $K_{i}=1$.

As a sample of calculation, we apply mechanical load equal to $400 \mathrm{~g}$. The overall transfer functions of the damper mass spring controlled system $\left(G_{s y s}\right)$ as mentioned in Eq. (13) will be calculated as in the following:

$$
G_{s y s}=\frac{0.47\left(s^{2}+s+1\right)}{0.0022 s^{3}+0.5683 s^{2}+2.7151 s+0.47}
$$

It can be displayed the unit step response results for the employed controlled system with using conventional PID controller unit and applying various values of mechanical load as shown in Fig. 3.

The main characteristics of the step input response have been summarized as shown in Table 1 .

According to the obtained results in Table 1, the performance of the response of the control system can be improved to become more acceptable. It will be tried to make a tuning process for the gain factors of the PID compensator unit via Matlab software program in order to get more convenience results for the main characteristics of the step input response for the employed controlled system. 


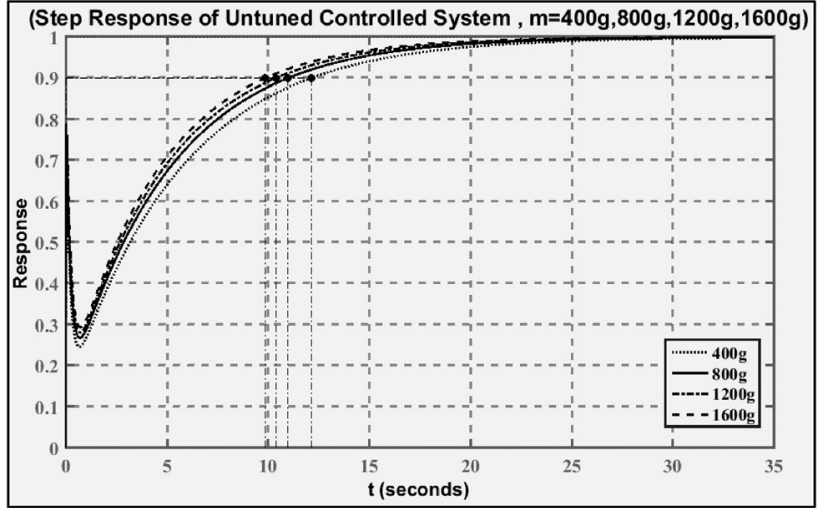

Fig. 3. The step response of the electromechanical damper mass spring with conventional PID controller unit

Table 1. The main characteristics of the step input response for the controlled damper mass spring system with using PID controller unit

\begin{tabular}{lrrrr}
\hline $\begin{array}{l}\text { Mechanical } \\
\text { load }\end{array}$ & $400 \mathrm{~g}$ & $800 \mathrm{~g}$ & $1,200 \mathrm{~g}$ & $1,600 \mathrm{~g}$ \\
\hline Rise time (s) & 12.1348 & 10.9968 & 10.3933 & 9.8695 \\
Settling time (s) & 21.0829 & 19.1275 & 18.0885 & 17.1852 \\
\hline
\end{tabular}

The tuning process of PID controller leads to gain overall transfer functions of the tuned damper mass spring controlled system as shown in Table 2.

The display of the step input results for the tuned control system with applying the selective range of the mechanical load will be obtained as shown in Fig. 4(a)-(d), respectively.

As mentioned in Fig. 4 with using the tuned PID controller unit, the response of the controlled system due to applying step input has been more acceptable but in the range of mechanical load value that lies between 400 and $1,200 \mathrm{~g}$. It can be clearly observed that the system will be unstable and has very large value of steady state error at the effect of applying 1,600 $\mathrm{g}$ of mechanical load. The characteristics of the tuned controlled damping system are listed as shown in Table 3.

To make an improvement for the response of the controlled system, the backstepping control technique will be employed to test the best behaviour of the damper mass spring controlled system. In the procedure of applying the backstepping control scheme, Eq. (28) will be modified as follows:

$$
u=\frac{1}{g(t)}\left(\tanh (-F(x, t))-k_{2} s+e_{1}+k_{1} \dot{e}_{1}-\ddot{x}_{d}\right)
$$

According to Eq. (29) and with taking $\left(k_{1}=30\right)$ and $\left(k_{2}=\right.$

Table 2. The transfer functions of the damper mass spring controlled system with tuned PID parameters

\begin{tabular}{lccc}
\hline Mechanical load $(\mathrm{g})$ & Displacement distance $(\mathrm{mm})$ & Position sensor signal $(\mathrm{mV})$ & Tuned controlled system \\
\hline 400 & 5.5 & 470 & $G_{\text {tuned }}=\frac{56 s^{3}+17.89 \mathrm{~s}^{2}+408.2 s+5633}{0.493}$ \\
800 & 6.3 & 600 & $G_{\text {tuned }}=\frac{3973}{0.8 s^{3}+17.89 s^{2}+408.2 s+3973}$ \\
1,200 & 7.2 & 730 & $G_{\text {tuned }}=\frac{433}{1.2 s^{3}+17.895^{2}+408.2 s+4330}$ \\
1,600 & 8.1 & 870 & $G_{\text {tuned }}=\frac{5327}{1.6 s^{3}+17.89 s^{2}+408.2 s+5327}$ \\
\hline
\end{tabular}

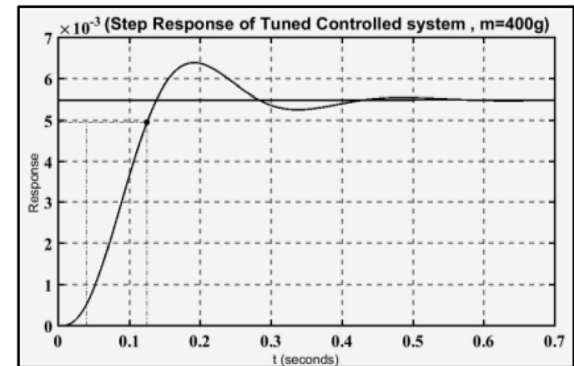

(a)

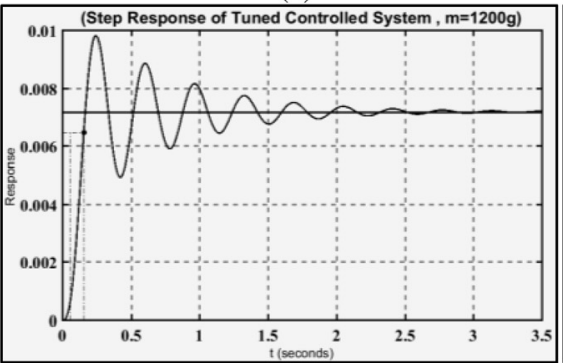

(c)

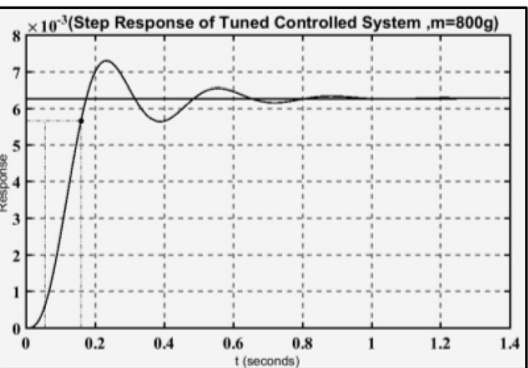

(b)

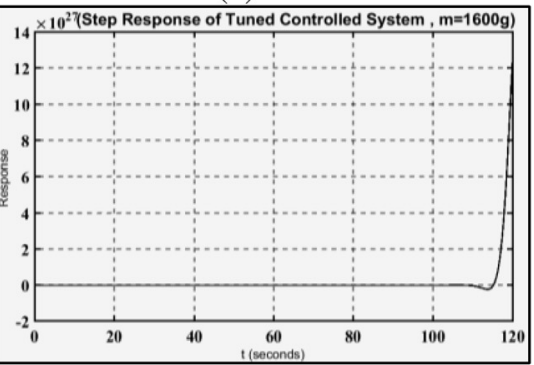

(d)

Fig. 4. The step response of the electromechanical damper mass spring with tuned PID controller unit (a) $\mathrm{m}=400 \mathrm{~g},(\mathrm{~b}) \mathrm{m}=800 \mathrm{~g}$, (c) $\mathrm{m}=1,200 \mathrm{~g}$ and $(\mathrm{d}) \mathrm{m}=1,600 \mathrm{~g}$ 
Table 3. The main characteristics of the step input response for the tuned controlled system

\begin{tabular}{lcccc}
\hline $\begin{array}{l}\text { Mechanical } \\
\text { load }\end{array}$ & $400 \mathrm{~g}$ & $800 \mathrm{~g}$ & $1,200 \mathrm{~g}$ & $1,600 \mathrm{~g}$ \\
\hline Rise time (s) & 0.0840 & 0.1038 & 0.0968 & $\mathrm{NaN}$ \\
Settling & 0.3937 & 0.6157 & 2.0895 & $\mathrm{NaN}$ \\
$\quad$ time (s) & & & & \\
Steady state & $8.5110 \times$ & $1.0565 \times$ & $1.0827 \times$ & $1.1963 \times$ \\
$\quad$ error & $10^{-6}$ & $10^{-5}$ & $10^{-5}$ & $10^{23}$ \\
\hline
\end{tabular}

where $(\mathrm{NaN})$; represents the undefined results and it is an abbreviation of 'Not A Number' in Matlab software package [22].

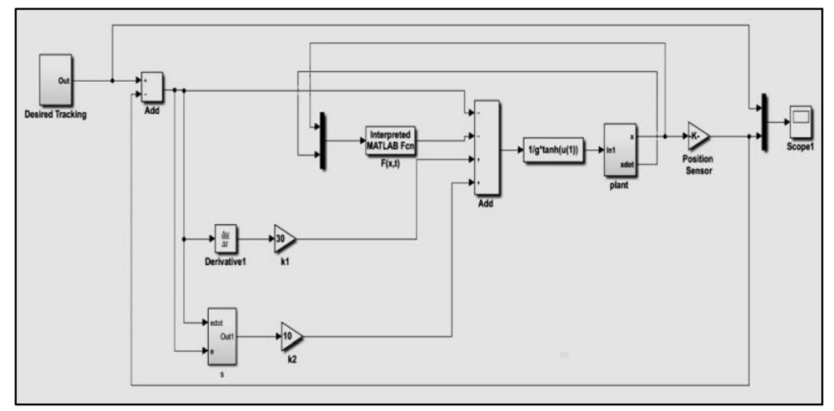

Fig. 5. The Matlab Simulink model of the damper mass spring controlled system with using back stepping control technique

10), then the Matlab Simulink model of the controlled damper mass spring system using backstepping control technique will be constructed as shown in Fig. 5.
Table 4. The main characteristics of the step response with backstepping control technique

\begin{tabular}{lccc}
\hline $\begin{array}{l}\text { Mechanical } \\
\text { load }(\mathrm{g})\end{array}$ & $\begin{array}{r}\text { Rise } \\
\text { time }(\mathrm{s})\end{array}$ & $\begin{array}{c}\text { Settling } \\
\text { time }(\mathrm{s})\end{array}$ & $\begin{array}{r}\text { Steady } \\
\text { state error }\end{array}$ \\
\hline 400 & 0.286285 & 0.488 & 0 \\
800 & 0.286361 & 0.4953 & 0 \\
1,200 & 0.286418 & 0.5265 & 0 \\
1,600 & 0.286488 & 0.5382 & 0 \\
\hline
\end{tabular}

The step input response of the controlled damper mass spring system with using backstepping control scheme can be displayed as shown in Fig. 6(a)-(d), respectively.

In Fig. 6, it was clearly observed that the response of the selected damper mass spring controlled system has been more accurate with zero values steady state errors than low value of stalling time equal to $0.53 \mathrm{~s}$ as in the case of applying mechanical load equal to $1,600 \mathrm{~g}$, leading to give better performance of the proposed control system. In summary, the main characteristics of the backstepping controlled model with step input can be listed as shown in Table 4 .

\section{CONCLUSIONS}

In this work, an implementation of several control techniques to realize the best performance of the conventional damper mass spring controlled system linked with position sensor has been carried out. According to the resulting theoretical and practical outcomes, the following conclusions can be drawn:

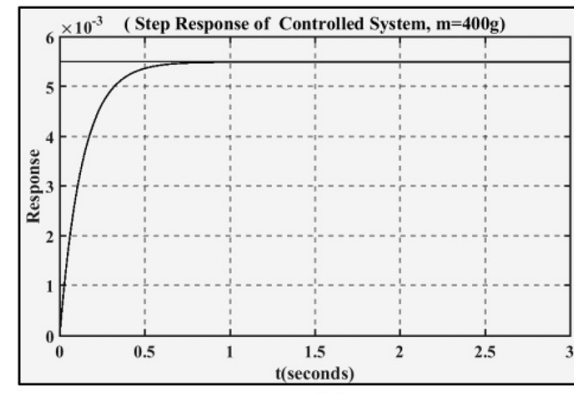

(a)

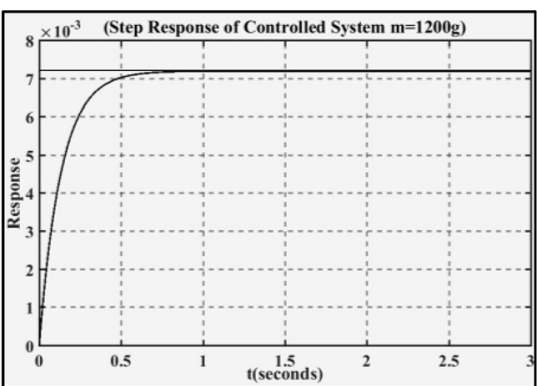

(c)

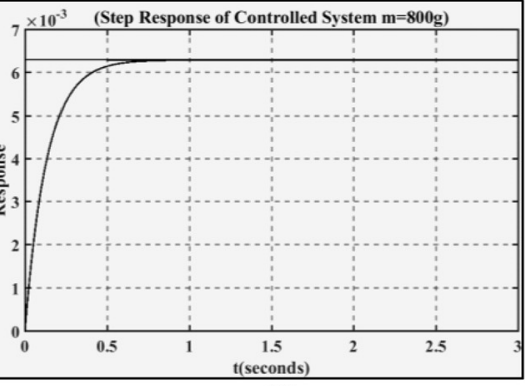

(b)

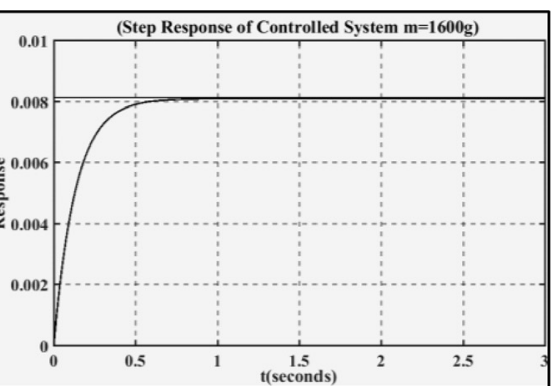

(d)

Fig. 6. The step response of the electromechanical damper mass spring with using backstepping controller unit (a) $\mathrm{m}=400 \mathrm{~g},(\mathrm{~b}) \mathrm{m}=800$ $\mathrm{g}$, (c) $\mathrm{m}=1,200 \mathrm{~g}$ and $(\mathrm{d}) \mathrm{m}=1,600 \mathrm{~g}$ 
1. The design of controlled models for the selective dynamical system has involved the practical results of the empirical laboratory work as well as the mathematical models of the suggested configuration of the damper mass spring system.

2. From the obtained simulation results it was found that the employed backstepping control technique can provide a more stable system, in comparison with the classical PID controller model especially when applying an extended value range of mechanical load.

3. The proposed backstepping control technique can be modified to give more reliability of control action with taking in consideration the physical parameters of the mechanical apparatus.

\section{REFERENCES}

[1] A. A. Aly and F. A. Salem, "Vehicle suspension systems control: a review," Int. J. Control Autom. Syst., vol. 2, no. 2, pp. 46-54, 2013.

[2] R. Debbarma and S. Hazari, "Mass distribution of multiple tuned mass dampers for vibration control of structures under earthquake load," Int. J. Emerg. Technol. Adv. Eng., vol. 3, no. 8, pp. 198-202, 2013.

[3] N. E. Kahveci and I. V. Kolmanovsky, "Control design for electromagnetic actuators based on backstepping and landing reference governor," IFAC Proc. Vol., vol. 43, no. 18, pp. 393-8, 2010.

[4] A. Agharkakli, G. S. Sabet, and A. Barouz, "Simulation and analysis of passive and active suspension system using quarter car model for different road profile," Int. J. Eng. Trends Technol., vol. 3, no. 5, pp. 636-44, 2012.

[5] A. V. Ojha and A. Khandelwal, "Control of nonlinear system using backstepping,” J. Res. Eng. Technol., vol. 4, no. 5, pp. 606-10, 2015.

[6] A. Humaidi, M. Hameed, and A. Hameed, "Design of blockbackstepping controller to ball and arc system based on zero dynamic theory," J. Eng. Sci. Tech., vol. 13, no. 7, pp. 2084-105, 2018.

[7] F. Abry, X. Brun, S. Sesmat, and E. Bideaux, "Non-linear position control of a pneumatic actuator with closed-loop stiffness and damping tuning," in 2013 European Control Conference (ECC) July 17, IEEE, 2013, pp. 1089-94.

[8] M. F. Badr, A. Nayeeif, and W. Mustafa, "Investigation the effect of the various stiffness coefficient on the controlled damper mass spring system based on the electromechanical sensor," Int. J.
Mech. Prod. Eng. Res. Dev. (IJMPERD), vol. 9, no. 3, pp. 243-56, 2019.

[9] J. S. Lin and I. Kanellakopoulos, "Nonlinear design of active suspensions," IEEE Contr. Syst. Mag., vol. 17, no. 3, pp. 45-59, 1997.

[10] R. Mellish, Backstepping Control Design for the Coordinated Motion of Vehicles in a Flowfield (Doctoral dissertation), 2011.

[11] M. Basri, M. Ariffanan, K. A. Danapalasingam, and A. R. Husain, "Design and optimization of backstepping controller for an under actuated autonomous quad rotor unmanned aerial vehicle," $T$. FAMENA, vol. 38, no. 3, pp. 27-44, 2014.

[12] M. A. M. Basri, A. R. Husain, and K. A. Danapalasingam, "Robust chattering free backstepping sliding mode control strategy for autonomous quad rotor helicopter," Int. J. Mech. Mechatron. Eng., vol. 14, no. 3, pp. 36-44, 2014.

[13] M. F. Rahmat, N. H. Sunar, S. Salim, , "Review on modeling and controller design in pneumatic actuator control system. Int. J. Smart Sens. Intell. Syst., vol. 4, no. 4, pp. 630-61, 2011.

[14] S. S. Ge, L. Huang, and T. H. Lee, "Position control of chained multiple mass-spring-damper systems: adaptive output feedback control approaches," Int. J. Control Autom. Syst., vol. 2, no. 2, pp. 144-55, 2004.

[15] Y. Fang, J. Fei, and Y. Yang, "Adaptive backstepping design of a micro gyroscope," Micromachines, vol. 9, no. 7, p. 338, 2018.

[16] D. G. Alciatore, Introduction to Mechatronics and Measurement Systems. Tata McGraw-Hill Education, 2007.

[17] R. H. Bishop, Ed. Mechatronic Systems, Sensors, and Actuators. Boca Raton, FL: CRC Press, 2008.

[18] J. J. d'Azzo and C. D. Houpis, Linear Control System Analysis and Design: Conventional and Modern. McGraw-Hill Higher Education, 1995.

[19] M. F. Badr, Y. Abdullah, and A. K. Jaliel, "Position control of the pneumatic actuator employing ON/OFF solenoids valve," Int. J. Mech. Mechatronics. Eng., vol. 17, pp. 29-37, 2017.

[20] R. L. Boylestad, Introductory Circuit Analysis: Pearson New International Edition: UEL. Pearson Higher Ed, 2013.

[21] M. F. Badr, "Modelling and Simulation of a Controlled Solenoid," in IOP Conference Series: Materials Science and Engineering (Vol. 433, No. 1, p. 012082). IOP Publishing, Nov. 2018.

[22] C. H. Houpis and S. N. Sheldon, Linear Control System Analysis and Design with MATLAB. CRC Press, 2013. 